\title{
Mode II Interlaminar Fracture Properties of Treated Silk Fibre/ Epoxy Composites at Low and High Temperature Range
}

\author{
Rozli Zulkifli* and Che Husna Azhari \\ ${ }^{1}$ Centre of Materials Engineering and Smart Manufacturing \\ Faculty or Engineering and Built Environment, Universiti Kebangsaan Malaysia \\ Bangi, 43600, Malaysia \\ *Corresponding author Email: rozlizulkifli@ukm.edu.my
}

\begin{abstract}
Composite materials have a wide range of applications including as an automotive components. In certain applications it is exposed to various heat conditions and might affect its mechanical properties. It is important to be able to predict the behavior of the composites under different temperature settings in order to prevent failure. The $\mathrm{G}_{\text {IIC }}$ properties of composite epoxy laminate with silk fibre at various temperatures have yet to be investigated by any researcher. This study was carried out to analyse the Mode II interlaminar fracture properties, $\mathrm{G}_{\text {IIC }}$ of the silk fibre / epoxy composite materials when treated with silane coupling agents at different test temperatures. This property is important since it provides the measure of the material's resistance to delamination crack propagation. Composite specimens were produced using compression moulding technique with sixteen layers of silk fabric. The matrix is an epoxy D.E.R 331 and Hardener Joint mine 905-3S. The weight ratio of mixing epoxy and hardener is 2:1. Six sets of sample were prepared using silk fibre which has undergone surface treatment for 24 hour using silane coupling agent surface treatment solution. Specimens were tested by Instron Universal Testing Machine using a three-point bending based on an end notched flexural (ENF) method. The tests were carried out at six different temperatures which are at $20{ }^{\circ} \mathrm{C}, 23{ }^{\circ} \mathrm{C}, 26{ }^{\circ} \mathrm{C}, 38{ }^{\circ} \mathrm{C}, 50{ }^{\circ} \mathrm{C}$ and $75{ }^{\circ} \mathrm{C}$. The temperature of the specimens during testing was monitored using a thermal imager in order determine the exact test temperature. It was found that as the temperatures increases, the mode II fracture toughness decreases by up to $71 \%$. The length of crack propagation shows that higher temperature leads to longer crack length. This could be due to the residual tension between the fibre and matrix as they have different thermal coefficient of expansion.
\end{abstract}

Keywords: Silk fibre; mode II interlaminar fracture; end-notched flexure; composites; temperature.

\section{Introduction}

Recently, woven Bombyx mori (B.mori) natural silk has been introduced as reinforcement in different polymeric matrix for possible application in automotive industry [1-4]. Some of its parameters has been investigated and measured while there remain many parameters yet to be studied. A review of the literature on this topic revealed that crashworthiness characteristic for has been investigated. Silk fibre has a very good strength to weight ratio and have the potential to be used as reinforcement materials in composites for applications which requires further weight reduction. Oshkovr et al. [1] investigated B.mori/Epoxy laminated composite square tube energy absorbers of varied lengths. Parameters measured includes: the crash force efficiency (CFE), and the total energy absorbed (E-total). Eshkoor et al. [2] in their work applied the use of trigger mechanism to further investigate the crashworthiness of the bombyx mori square composite structure.

Dynamic impact test has also been investigated by Ude et al. [4], in which impact toughness of B.mori silk fibre as a reinforced composite face-sheet for core sandwich was the focus of the investigation. There was no found record on mode II interlaminar fracture toughness of Bombyx mori natural silk epoxy composite. There was also no record on the effect of temperature on the interlaminar fracture of B.mori/epoxy composite. It is then possible to state that the mode II interlaminar fracture toughness $\left(\mathrm{G}_{\text {IIC }}\right)$ on silk fibre/epoxy composite is a novel investigation, since it has not been investigated by any researcher. Interlaminar delamination is one of the most common and potentially dangerous modes of failure in composite structures. It is a known fact, that even high performance laminated composites are susceptible to delamination failure. Delamination causes loss of strength and stiffness, which may lead to sudden failure problems. Delamination promotes localised buckling phenomena and its detection requires sophisticated non-destructive assessment procedures, which are always expensive. Based on these facts, delamination is one of the major obstacles in achieving the full usage of this advanced composite material in engineering structures [5-6]

Different test method has been used to measure the ability of composite materials to resist delamination, most often called interlaminar fracture toughness (Gc). The double cantilever beam (DCB) test method is currently standardised for the measurement of the mode I interlaminar critical strain energy release rate, GIc, of unidirectional (UD) laminates. However, there is still no compromise on which is the best mode II test method among the end notched flexure (ENF), the end-load split (ELS) and four-point end-notched flexure (4ENF) [7]. Nevertheless, owing to the simple set-up of ENF specimen, it has been the most used [8]. Various investigations have been reported on mode II fracture of multidirectional (MD) laminates [6-9]. However, the need for this study rose from the fact that an investigation of the interlaminar fracture 
toughness of B.mori fibre/epoxy composite will determine its potential as a structural materials for various applications.

Polymer-matrix composites are viscoelastic materials and their mechanical properties are significantly influenced by temperature. The aim of this research is to determine the effect of temperature on Mode II Interlaminar fracture toughness of silk fibre/epoxy using ENF method. Crack that occurs due to the test will be analysed and the crack length of the specimen after the test will be measured to identify the extent of specimen failure.

\section{Experimental Method}

\subsection{Materials}

The materials used in this experiment were: epoxy resin, type (DER 331), Jointmine hardener, type (905-35) employed to facilitate curing, and plain woven Bombyx mori silk fabric are as shown in Figure 1. Treated B.mori silk fibre were used to prepare the sample specimen and the properties of the silk and epoxy are listed in Tables 1 and 2.
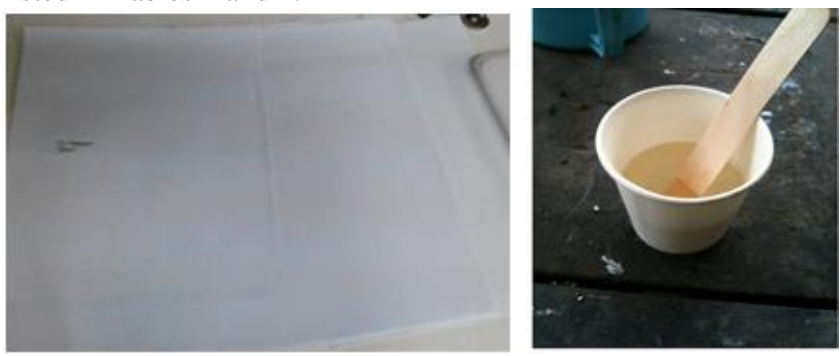

Fig. 1: Plain woven Bombyx mori silk fibre and epoxy resin.

Table 1: Properties of DER 331 epoxy
\begin{tabular}{|c|c|}
\hline Materials & Epoxy DER 331 \\
\hline Density $\left(\mathrm{kg} / \mathrm{m}^{3}\right)$ & 1084 \\
\hline Compressive strength $(\mathrm{MPa})$ & 131 \\
\hline Tensile strength $(\mathrm{MPa})$ & 63.6 \\
\hline Cure time $(\mathrm{hr})$ & $9-12$ \\
\hline Cure temperature $\left({ }^{\circ} \mathrm{C}\right)$ & 23.9 \\
\hline
\end{tabular}

Table 2: Properties of Bombyx mori plain woven natural silk fabric

\begin{tabular}{|c|c|}
\hline Materials & Bombyx Mori \\
\hline Density $\left(\mathrm{kg} / \mathrm{m}^{3}\right)$ & 1.4 \\
\hline Thickness $(\mathrm{mm})$ & 0.42 \\
\hline Modulus of elasticity $\left(\mathrm{Nm}^{2}\right)$ & 22 \\
\hline Ultimate strength $\left(\mathrm{Nm}^{2}\right)$ & 11 \\
\hline Elongation $(\%)$ & 9 \\
\hline
\end{tabular}

\subsection{Specimen Preparation}

Six sets of specimen were fabricated and tested. Each specimen of this composite will be fabricated using 16 layers of silk fibre. For this research, composites epoxy laminated by silk fibre that are already treated by silane solution will be used. Epoxy matrix for the composite specimen was supplied by Hexion Specialty Chemicals. 3-aminopropyl triethoxysilane coupling agent by Aldrich was used for the surface treatment of silk fibre. Ethanol was used to dilute the silane coupling agent and silk fibre was treated for a 24 hour period of time in order to improve surface adhesion. Concentration of silane solution use for silk fibre surface treatment is at $2 \%$, it gives an effective function of silane solution to enhance adhesion between the epoxy and silk fibres [10-11]. The composite materials used in this experiment were prepared in a hot press machine. Figure 2 and 3 show the photo of the silane, ethanol and the silk fibres being dryed inside a furnace.

During moulding processes, a piece of aluminum foil will be included in middle of silk fibre layer during the fabrication process. It is used to facilitate process of delamination to occur during the test for this composite. The foil has to be sufficiently thin so that the moulding process of the composite specimens will not be affected. All specimens will undergo cutting process and its geome- try will follow ASTM standard. Sand paper is also use to make cutting side more smooth before undergoing interlaminar fracture toughness Mode II tests. Lastly, the composite specimen is being placed inside a hot press machine to form the final specimens for the ENF test.
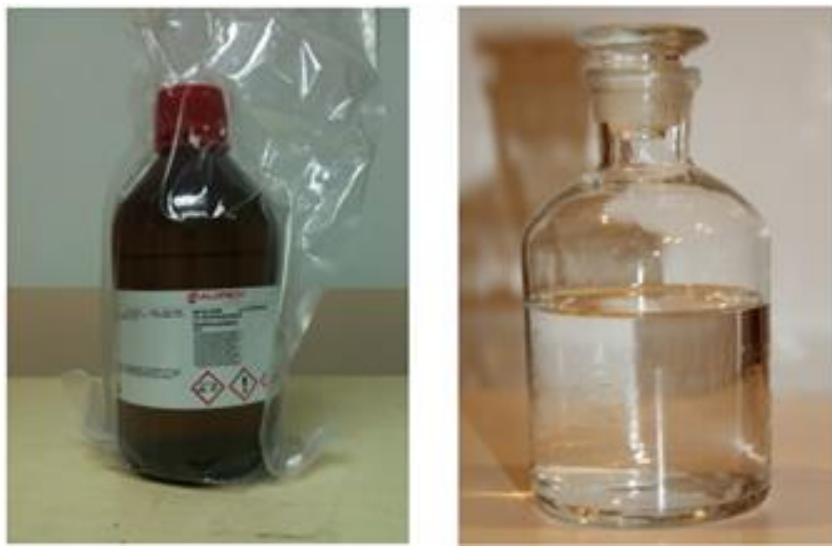

Fig. 2: Silane coupling agent and ethanol.

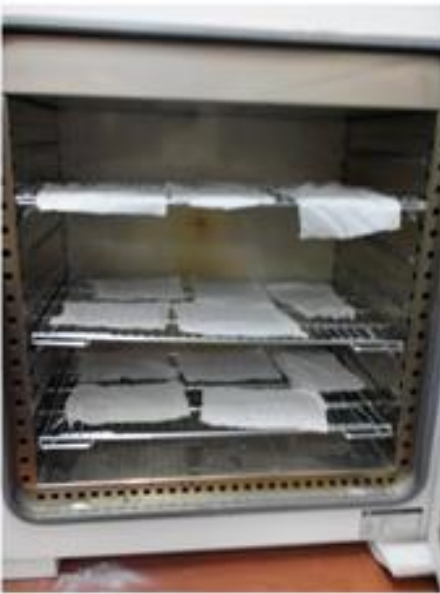

Fig. 3: Treatment of silk fibre with silane coupling agent and ethanol inside an oven.

All mode-II tests were performed using a three-point bending; an end notched flexural (ENF). The specimens were positioned in the three-point bend fixture with a total span of $100 \mathrm{~mm}$. The load was introduced to the specimen by an Instron Universal Testing Machine (UTM). The end-notched flexure (ENF) specimen is performed the test for measuring the resistance to delamination under Mode II loading. Rate of speed use for the test is 5.00 $\mathrm{mm} / \mathrm{min}$. Figure 4 and 5 show the schematic diagram and photo of the test being carried out inside the heating chamber. Figure 6 and 6 show the thermal image of the specimen during the test and the overall temperature distribution inside the heating chamber in order to determine the temperature of the specimen during testing.

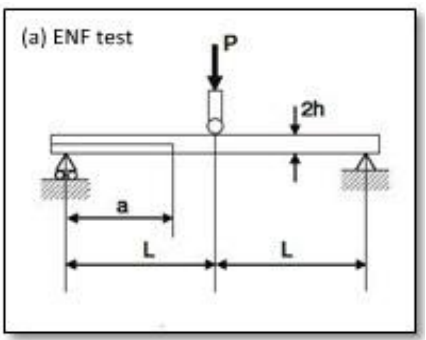

Fig. 4: Protocol diagram for ENF test and image of the specimen during testing 

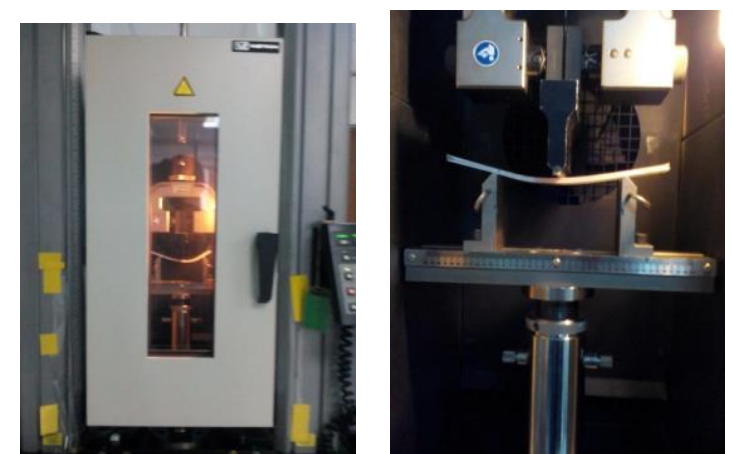

Fig. 5: Protocol diagram for ENF test and image of the specimen during testing

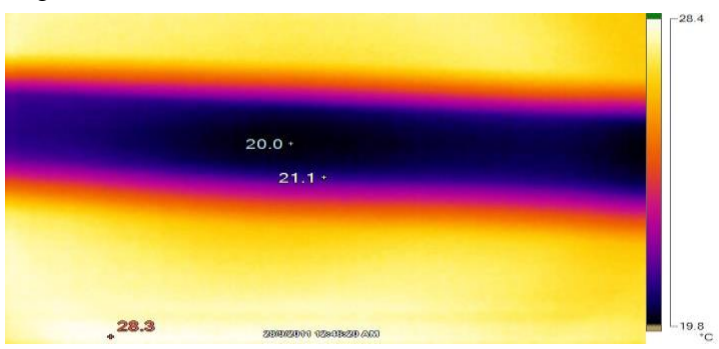

Fig. 6: Thermal image of the specimens during the ENF test.

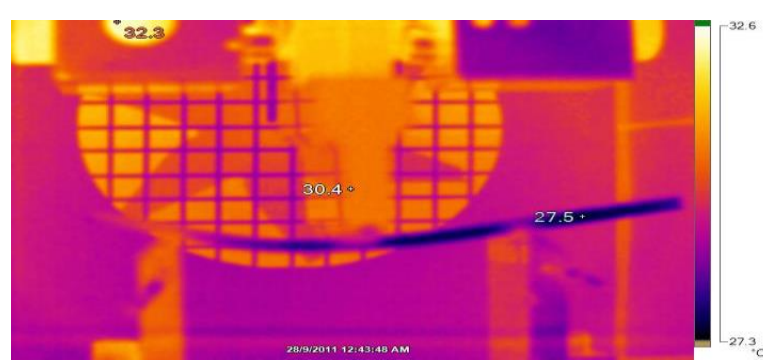

Fig. 7: Thermal image inside the heating chamber during the test.

\section{Results and Discussion}

The ENF test was conducted to determine the initiation value of Mode II fracture toughness because of the instability of crack growth. Results of maximum flexure load and $\mathrm{G}_{\text {IIC }}$ obtained for all test temperature are as shown in Table 3. All value of Mode II interlaminar fracture toughness for ENF test was plotted and is shown in Figure 8.

Table 3: Value of Mode II fracture toughness, $\mathrm{G}_{\text {IIC (ENF) }}$ for ENF test

\begin{tabular}{|c|c|c|}
\hline Temperature $\left({ }^{\circ} \mathrm{C}\right)$ & $\begin{array}{c}\text { Maximum } \\
\text { Flexure Load }(\mathrm{N})\end{array}$ & $\begin{array}{c}\mathrm{G}_{\text {IIC }(\mathrm{ENF})} \\
\left(\mathrm{J} / \mathrm{m}^{2}\right)\end{array}$ \\
\hline 20 & 169.5 & 86.5 \\
\hline 23 & 165.7 & 90.7 \\
\hline 26 & 170.8 & 128.7 \\
\hline 38 & 100.1 & 71.3 \\
\hline 50 & 76 & 45.2 \\
\hline 75 & 21.7 & 37.2 \\
\hline
\end{tabular}

An increase in test temperature from room temperature decreases the value of Mode II interlaminar fracture toughness, $\mathrm{G}_{\text {IIC (ENF) }}$ by up to $71 \%$. While reducing the temperature to $20{ }^{\circ} \mathrm{C}$ also reduces the $\mathrm{G}_{\mathrm{IIC} \text { (ENF) }}$ by up to $33 \%$. This could be due to the difference expansion or contraction coefficient between the fibre and the matrix. Crack analysis was done to see more closely propagation of crack from the aluminum foil pre-cracked starting point after the test. Figure 9 shows the crack length of $6 \mathrm{~mm}$ for the specimen tested at $75{ }^{\circ} \mathrm{C}$. The value of crack length for specimen tested at higher temperature is longer compared to the specimen tested at lower temperature. This shows that the matrix expansion at higher temperature reduces the surface adhesion on the fibre surface. At lower temperature, on the other hand, provide the reverse effect. The matrix became brittle and undergoes contraction which leads to the same effect of reduce surface adhesion.

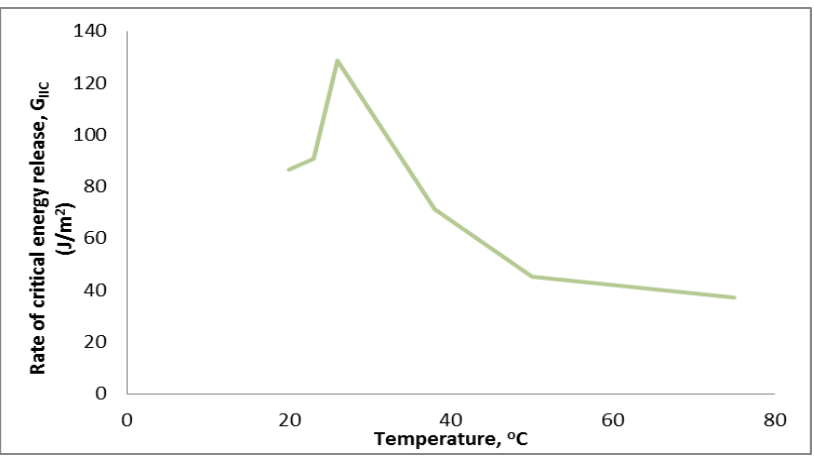

Fig. 8: Graph of Mode II interlaminar fracture toughness for each specimen for ENF test.

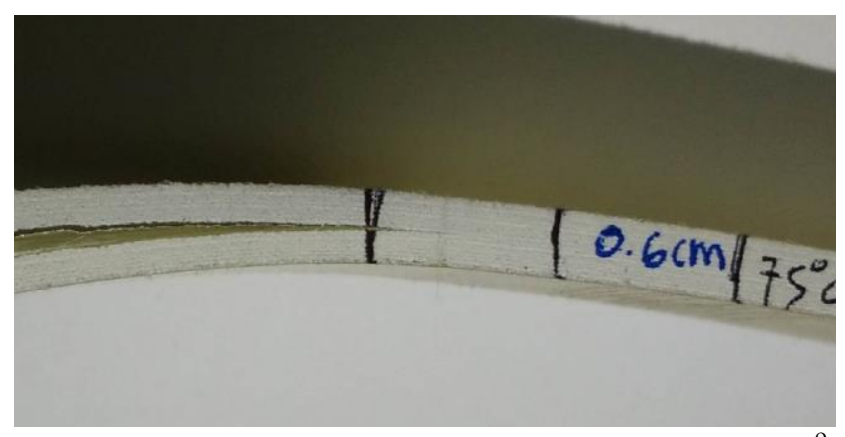

Fig. 9: Crack length of the composite specimen after the test at $75{ }^{\circ} \mathrm{C}$ which is at $6 \mathrm{~mm}$ from the pre-cracked point

Other effect includes sliding along the fibre-matrix interface accompanying matric cracking leads to the longer propagation of crack at other than room temperature. The linear temperature expansion coefficient for epoxy is between $45-65 \times 10^{-6} \mathrm{~m} / \mathrm{m} \mathrm{K}$ while silk fibre has a negative thermal expansion coefficient. As a result, at testing temperature below or above the bonding temperature the matrix sustains residual tension and the fibre-matrix interface is subjected to a residual compression. Further analysis of the fracture surface will be the next step of the research.

\section{Conclusion}

From the experimental data obtained, the value of Mode II interlaminar fracture toughness, $\mathrm{G}_{\mathrm{IIC}(\mathrm{ENF})}$ for End Notched Flexure (ENF) test method is greatly affected by the test temperature. Test temperature at lower and higher than the room temperature which is when the fibre and matrix were first bonded will results in the residual tension between the interfaces. Cracking of matrix and fibre sliding occurred during the test which results in reduced $\mathrm{G}_{\text {IIC }}$ (ENF) value. From this result, it can be concluded that the test temperature has greatly affected the Mode II interlaminar fracture

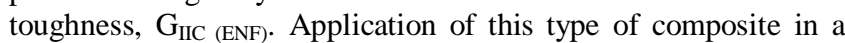
prolong exposure at lower or higher temperature than the room temperature is not recommended due to this effect.

\section{Acknowledgement}

This research project was supported by the UKM research grant under DLP-2013-030. Their financial support is gratefully acknowledged.

\section{References}

[1] Oshkovr, S. A., R. A. Eshkoor, et al. (2012). "Crashworthiness characteristics investigation of silk/epoxy composite square tubes." Composite Structures 94(8): 2337-2342.

[2] Eshkoor, R.A., Oshkovr, S.A., Sulong, A.B., Zulkifli, R., Ariffin, A.K., Azhari, C.H. (2013). "Effect of trigger configuration on the crashworthiness characteristics of natural silk epoxy composite tubes." Composites Part B: Engineering 55(0): 5-10. 
[3] Eshkoor, R.A., Oshkovr, S.A., Sulong, A.B., Zulkifli, R., Ariffin, A.K. \& Azhari, C.H. (2013). "Comparative research on the crashworthiness characteristics of woven natural silk/epoxy composite tubes." Materials \& Design 47(0): 248-257.

[4] Ude, A. U., A. K. Ariffin, et al. (2013). "Impact damage characteristics in reinforced woven natural silk/epoxy composite face-sheet and sandwich foam, coremat and honeycomb materials." International Journal of Impact Engineering 58(0): 31-38.

[5] Mouritz, A. P., C. Baini, et al. (1999). "Mode I interlaminar fracture toughness properties of advanced textile fibreglass composites." Composites Part A: Applied Science and Manufacturing 30(7): 859-870.

[6] Miyagawa, H., C. Sato, et al. (2001). "Mode II interlaminar fracture toughness of multidirectional carbon fiber reinforced plastics cracking on 0//0 interface by Raman spectroscopy." Materials Science and Engineering: A 308(1-2): 200-208.

[7] Morais, A. B. d. (2004). "Mode II interlaminar fracture of blass/epoxy multidirectional laminates." Composite: Part A 35: 265-272.

[8] A.B. Pereira, A. B. d. M. (2004). "Mode II interlaminar fracture of glass/epoxy multidirectional laminates." Composites: Part A 35: $265-272$.

[9] Wang, F., Z. Shao, et al. (2013). "Mode II interlaminar fracture properties of Moso bamboo." Composites Part B: Engineering 44(1): 242-247.

[10] Zulkifli, R., Azhari, C.H., Ghazali, M.J., Ismail, A.R. and Sulong, A.B. (2009). " Interlaminar Fracture Toughness of Multi-Layer Woven Silk/Epoxy Composites Treated with Coupling Agent". European Journal of Scientific Research 27(3): 454-462.

[11] Zulkifli, R., Azhari, C.H., (2010). "Interfacial Treatment of MultiLayer Woven Silk/Epoxy Composites, International Review of Mechanical Engineering”, 4(1): 1-6. 